Scaling Laws in

Ice Mechanics and

Ice Dynamics

Proceedings of the IUTAM Symposium held in Fairbanks, Alaska, U.S.A., 13-16 June 2000

Edited by

\section{J.P. DEMPSEY}

Clarkson University,

Department of Civil and Environmental Engineering, Potsdam NY, U.S.A.

and

\section{H.H. SHEN}

\section{Clarkson University,}

Department of Civil and Environmental Engineering, Potsdam NY, U.S.A.

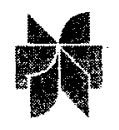

KLUWER ACADEMIC PUBLISHERS

\section{SCALING LAWS FOR SEA ICE FRACTURE}

\section{Zdenēk P. Bažant}

W.P. Murphy Professor of Civil Engineering and Materials Science Northwestern University, Evanston, Illinois 60208, USA

z-bazant@northwestern.edu

Abstract Based on the premise (recently validated by Dempsey's in-situ tests) that large-scale failure of sea ice is governed by cohesive fracture mechanics, the paper presents simplified analytical solutions for (1) the load capacity of floating ice plate subjected to vertical load and (2) the horizontal force exerted by an ice plated moving against a fixed structure. The solutions clarify the fracture mechanism and agree with the previous numerical simulations based on cohesive fracture mechanics. They confirm the presence of a strong deterministic size effect. For the case of vertical load, the size effect approximately follows the size effect law proposed in 1984 by Bažant. In the case of an ice plate moving against a fixed obstacle, radial cleavage of the ice plate in the direction opposite to ice movement causes a size effect of structure diameter which follows linear elastic fracture mechanics for small enough diameters but becomes progressively weaker as the diameter increases. The present solutions contradict the earlier solutions based on material strength or plasticity theories, which exhibit no size effect.

\section{Introduction}

Many studies have treated sea ice failure according to either plastic limit analysis or elasticity with a strength limit (see reviews in Kerr, 1996; and Bažant 2000 , 2002). These theories exhibit no size effect on the nominal strength of structure. When size effect was observed in tests, it was explained by Weibull theory of strength randomness. However, such an explanation of size effect is dubious because the maximum load in ice failure is usually not reached at the initiation of fracture but only after large stable crack growth (e.g. Bažant and Planas 1998, Bažant 1997a, Bažant and Chen 1997). Rather, the explanation must be sought in quasibrittle fracture mechanics. Recently, fractality of fracture surfaces or microcrack distributions was suggested as a source of structural size effects, but this idea also does not pass mechanics scrutiny (Bažant1997b).

Various recent experiments (Dempsey 1991, DeFranco and Dempsey 1994, DeFranco, Wei and Dempsey 1991), especially Dempsey's in-situ tests of record-size specimens (Dempsey et al. 1999a,b; Mulmule et al. 1995; Dempsey et al. 1995), indicate that sea ice does follow fracture mechanics and on scales larger than about $10 \mathrm{~m}$ is very well described by linear elastic fracture mechanics (LEFM). Consequently, the size effects of fracture mechanics (Bažant and Planas 1998; Bažant and Chen 1997, Bažant 2001) must get manifested in all the failures in which large cracks grow stably prior to reaching the maximum load. This includes two fundamental problems: (1) vertical load capacity of floating ice plate (penetration fracture), and (2) the maximum horizontal force exerted on a fixed structure by a moving ice plate. The former has been analyzed by fracture mechanics at various

195

J.P. Dempsey and H.H. Shen (eds.)

IUTAM Symposium on Scaling Laws in Ice Mechanics and Ice Dynamics, 195-207.

(1) 2001 Kluwer Academic Publishers. Printed in the Netherlands. 
levels of sophistication in several recent studies; see Bažant and Li (1994), Li and Bažant (1994), Dempsey et al. (1995), Bažant and Kim (1998), of which the last presents rather realistic numerical simulation confirming a strong deterministic size effect. Acoustic observations also suggest a size effect ( $\mathrm{Li}$ and Bažant 1998).

Quasibrittle fracture analysis of another problem, namely the large-scale thermal bending fracture of floating ice (Bažant 1992), also indicated strong size effect, following, however, a different law. So did the analysis of ice plate failure subjected to a vertical line load (Bažant 2001b, Bažant and Guo, 2001). These two problems, however, are beyond the scope of this paper.

The purpose of this article is to summarize the recent detailed numerical studies of size effect at Northwestern University and briefly outline a new simplified fracture analysis of size effect which is based on the technique of asymptotic matching, an approach that leads to explicit formulae. This study (which was described in much more detail in the preprint distributed at the Fairbanks workshop, Bažant 2000), will appear in full detail in the forthcoming journal article by Bažant (2002). Owing to space limit, discussions of previous ice fracture and scaling studies (Ashton 1986, Atkins 1975, Dempsey et al, 1995, 1999a, Goldstein and Osipenko 1993, Palmer 1983, Ponter 1983, Slepyan 1990, etc.) must be relegated to that article. 2. Review of Numerical Analysis of Vertical Penetration Bažant and Kim (1998) conducted a detailed numerical analysis of vertical load penetration, for which the typical fracture pattern is shown in Fig. 1a. The radial cracks at maximum load penetrate through only a part of ice thickness (Dempsey et al. 1995, Bažant and Li 1995); Fig,. 1b,c. The radius of each crack is divided by nodes into vertical strips in each of which the crack growth obeys Rice and Levy's (1972) nonlinear 'line-spring' model relating the normal force $N$ and bending moment $M$ in the cracked cross section to the relative displacement $\Delta$ and rotation $\theta$ (Fig. 1b). The following ice characteristics have been assumed tensile strength $f_{t}^{\prime}=0.2 \mathrm{MPa}$, fracture toughness $K_{c}=0.1 \mathrm{MPa} \sqrt{\mathrm{m}}$, Poisson ratio $\nu=0.29$, and Young's modulus $E=1.0 \mathrm{GPa}$, with the corresponding values: fracture energy $G_{f}=K_{c}^{2} / E=10 \mathrm{~J} / \mathrm{m}^{2}$, and Irwin's fracture characteristic length $l_{0}=\left(K_{c} / f_{t}^{\prime}\right)^{2}=0.25 \mathrm{~m}$.

The analysis is based on a simplified version of the cohesive crack model in which the vertical crack growth in each vertical strip is initiated according to a strength criterion. The cross section behavior is considered to be elastic-plastic until the yield envelope in the $(N, M)$ plane is crossed by the point $(N, M)$ corresponding to fracture mechanics. For ease of calculations, a non-associated plastic flow rule corresponding to the vector $(\mathrm{d} \Delta, \mathrm{d} \theta)$ based on fracture mechanics is assumed. To suppress moment singularity under concentrated load $P$, the load is replaced by a distributed load along a small circle centered at the load point.

Fig. 1e displays, with a strongly exaggerated vertical scale, the calculated crack profiles at subsequent loading stages. Fig. If shows the numerically calculated plot of the radial crack length $a$ versus the ice thickness $h$ ('fracture length' means the radial length of open crack, and 'plastic length' the crack length up to the tip of plastic zone). This plot reveals that, except for very thin ice, the radial crack length $a \approx c_{h} h$ where $c_{h} \approx 24$

The size effect is understood as the dependence of the nominal strength $\sigma_{N}$ on the structure size, which is here represented by the ice thickness, $h$. For the vertical penetration problem, we define $\sigma_{N}=P / h^{2}$ where $P=$ load. The data points in Fig. 1g show, in logarithmic scales, the numerically obtained size effect plot of the normalized $\sigma_{N}$ versus the relative ice thickness. The initial horizontal
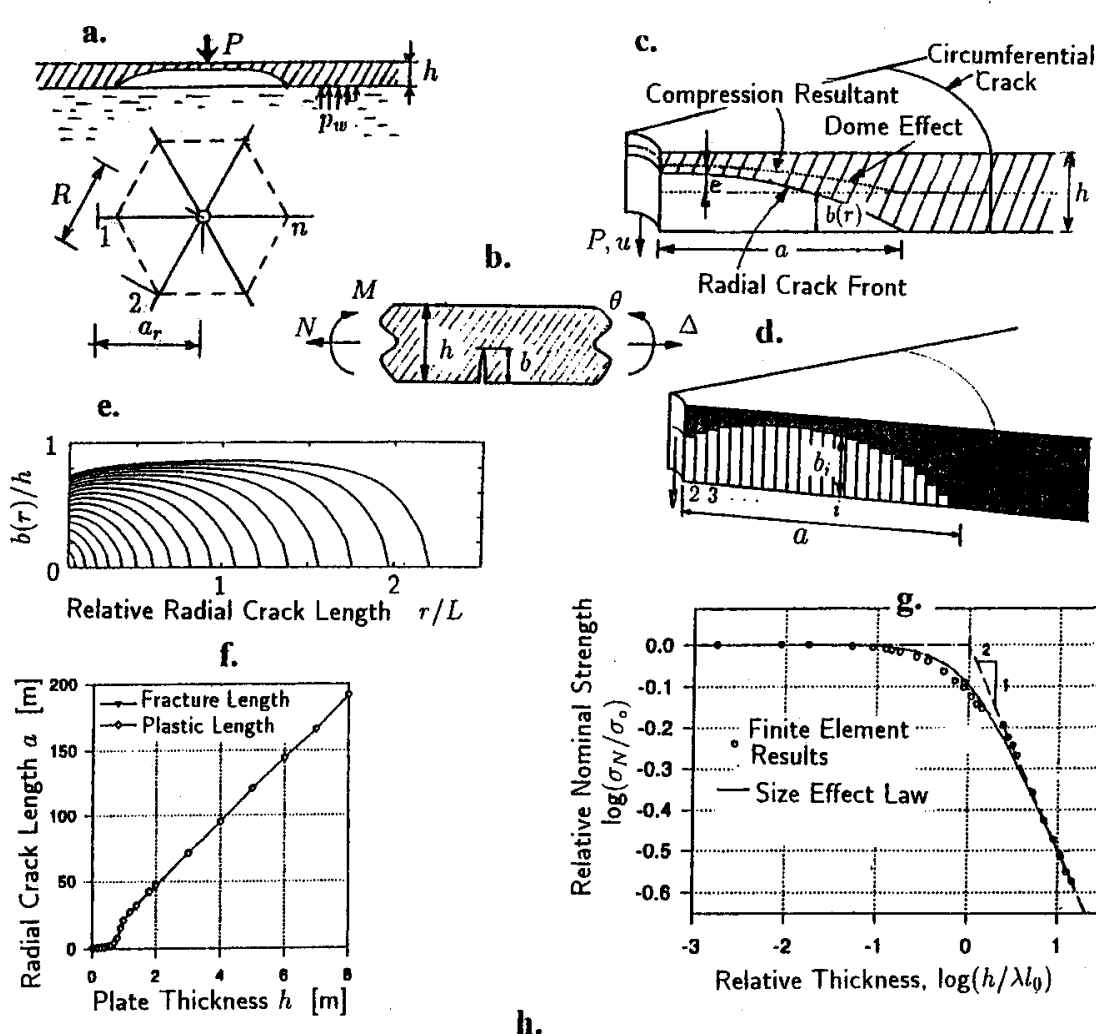

Compression Resultant
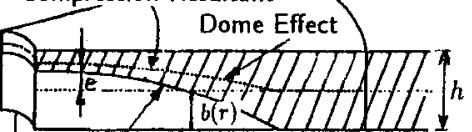

$P, u \nrightarrow+1$

Radial Crack Front

$\triangle$ d.
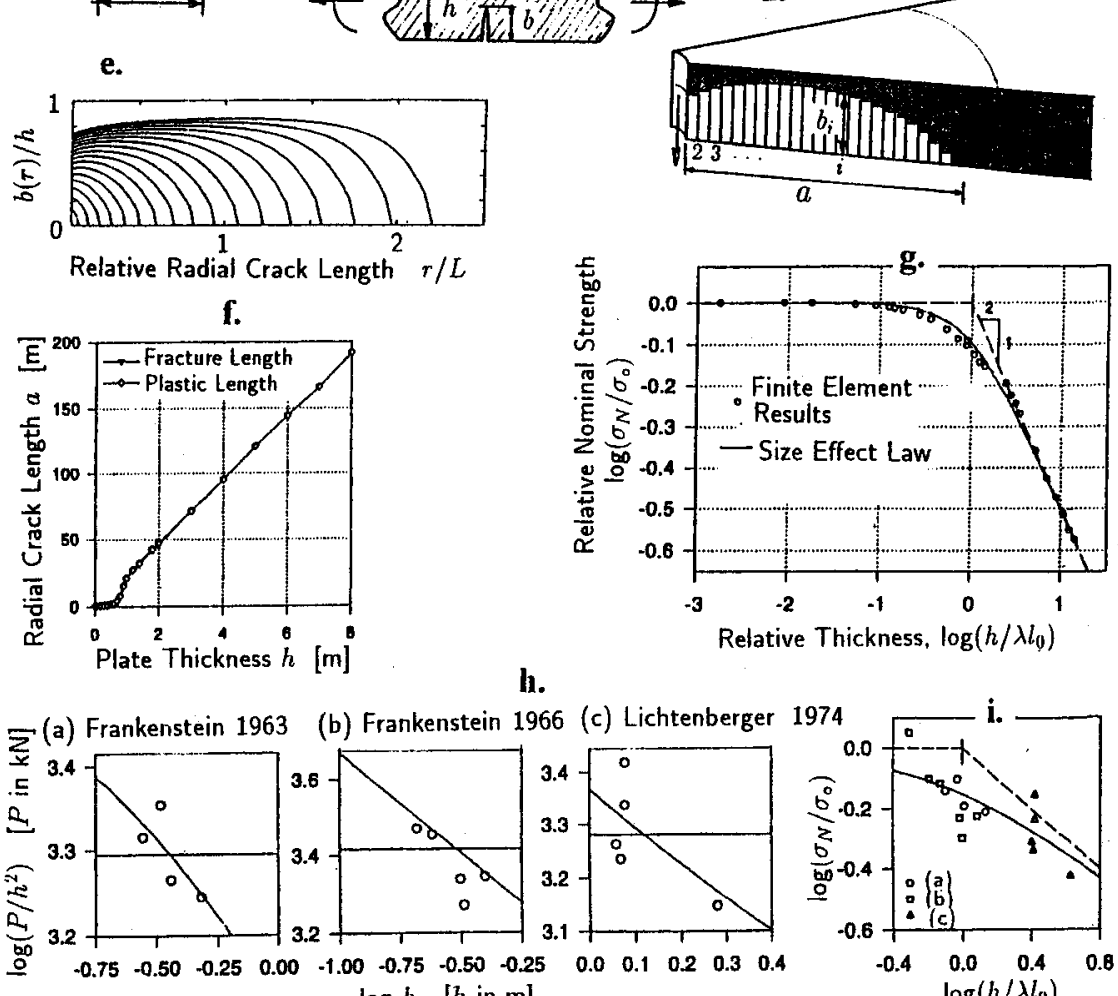

$\log h \quad[h$ in $\mathrm{m}]$

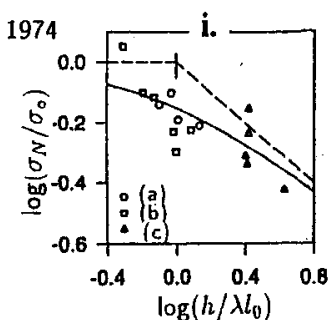

Figure 1: Vertical penetration fracture problem analyzed by Bažant and Kim (1998), main numerical results, and comparison with field tests of Frankenstein $(1963,1966)$ and Lichtenberger (1974). 
portion, for which there is no size effect, corresponds to ice thinner than about 20 $\mathrm{cm}$.

Since the model of Bažant and Kim includes plasticity, it can reproduce the classical solutions with no size effect. The ice thickness at the onset of size effect depends on the ratio of ice thickness to the fracture characteristic length, $h / l_{0}$. For realistic ice thicknesses $h$ ranging from $0.1 \mathrm{~m}$ to $6 \mathrm{~m}$, the computer program would yield perfectly plastic response with no size effect if the fracture characteristic length $l_{0}$ were at least $100 \times$ larger, i.e., at least $25 \mathrm{~m}$. This would, for instance, happen if either $f_{t}^{\prime}$ were at least $10 \times$ smaller $\left(f_{t}^{\prime} \leq 0.01 \mathrm{MPa}\right)$ or $K_{c}$ at least $10 \times$ larger $\left(K_{c} \geq 10 \mathrm{MPa} \sqrt{\mathrm{m}}\right)$. The entire diagram in Fig. 1g would then be horizontal.

The curve in Fig. 1g is the optimum fit of the numerically calculated data points by the generalized size effect law proposed in Bažant (1985). The final asymptote has slope $-1 / 2$, which means that the asymptotic size effect is $\sigma_{N} \propto h^{-1 / 2}$, the same as for LEFM with similar cracks, and not $h^{-3 / 8}$ as proposed by Slepyan (1990) and by Bažant and $\mathrm{Li}(1994)$. The $-3 / 8$ power scaling would have to apply if the radial cracks at maximum load were full-through bending cracks. The $-1 / 2$ power scaling may be explained by the fact that during failure the bending cracks are not full-through and propagate mainly vertically, which is supported by the calculated crack profiles in Fig. 1e (for thermal bending fracture, though, exponent $-3 / 8$ is valid; Bažant 1992)

By fitting of the size effect data in Fig. $1 \mathrm{~g}$, the following generalized size effect law (Bažant 1985; Bažant and Planas 1998) has been calibrated (see the curve in Fig. 1g): $\sigma_{N}=B f_{t}^{\prime}\left[1+\left(h / \lambda_{0} l_{0}\right)^{r}\right]^{-1 / 2 r}$ where $B=1.214, \lambda_{0}=2.55, m=1 / 2$, $r=1.55$ and $l_{0}=0.25 \mathrm{~m}\left(f_{t}^{\prime}=0.2 \mathrm{MPa}\right.$ in Fig. $\left.1 \mathrm{~g}\right)$. The test data available for checking this formula are very limited. The data points in Fig. $1 \mathrm{~h}$ represent the results of the field tests by (Frankenstein 1963,1966) and Lichtenberger (1974), and the curves show the optimum fits with the size effect formula verified by numerical calculations. After optimizing the size effect law parameters by fitting the data in the three plots in Fig. 1h, the data and the optimum fit are combined in the dimensionless plot in Fig. 1i.

Interesting discussions of Bažant and Kim's (1998) study were published by Dempsey (2000) and Sodhi (2000) and rebutted by the authors. Sodhi criticized the neglect of creep in Bažant and Kim's analysis. Intuition suggests that the influence of creep might be like that of plasticity, which tends to increase the process zone size, thereby making the response less brittle and the size effect weaker. But the influences of creep and plasticity are very different. This is documented by studies of concrete [e.g. Bažant and Gettu (1992); Bažant et al. 1993; Bažant and Planas (1998); and especially Bažant and Li (1997), and Li and Bažant (1997)] which show that creep always makes the size effect due to crack growth stronger. In the plot of $\log \sigma_{N}$ versus $\log$ (size), a decrease of loading rate causes a shift to the right, toward the LEFM asymptote, which means that the size effect is intensified by creep, contrary to the opinion of Sodhi. The physical reason, clarified by numerical solutions with a rate-dependent cohesive crack model ( $\mathrm{Li}$ and Bažant 1997), is that the highest stresses in the fracture process zone get relaxed by creep, which tends to reduce the effective length of the fracture process zone. The shorter the process zone, the higher is the brittleness of response and the stronger is the size effect. It thus transpires that, to take creep into account, it suffices to reduce the value of fracture energy and decrease the effective length of the fracture process zone.

\section{Approximate Analysis of Vertical Penetration}

An ice plate floating on water behaves exactly as a plate on Winkler elastic foundation (Fig. 1a), with a foundation modulus equal to the specific weight of water, $\rho$. Failure under a vertical load is known to involve formation of radial bending cracks in a star pattern (shown in a plan view in Fig. 1a). These radial cracks do not reach through the full ice thickness before the maximum load is reached (Dempsey et al. 1995, Bažant and Li 1995, Bažant and Kim 1998). Rather, they penetrate at maximum load to an average depth of about $0.8 \mathrm{~h}$ and maximum depth $0.85 \mathrm{~h}$ where $h$ is the ice thickness (Fig. 2a). The maximum load is reached when polygonal (circumferential) cracks, needed to complete the failure mechanism, begin to form (dashed lines in Fig. 1a).

Sea ice is not sufficiently confined to behave plastically (this is for example confirmed by the absence of yield plateau apparent in the load-deflection diagrams measured for instance by Sodhi 1998). Sea ice is a brittle material (e.g. Dempsey 1991; DeFranco and Dempsey 1992, 1994; DeFranco et al. 1991; Bažant 1992a,b; Bažant and Li, 1994; $\mathrm{Li}$ and Bažant 1994; Bažant and Kim 1998), and so the analysis must be based on the rate of energy dissipation at the crack front and the rate of energy release from the ice-water system.

Dimensional analysis, or alternatively a transformation of the partial differential equation for the bending of a plate on Winkler foundation to dimensionless coordinates, shows that the behavior of the plate is fully characterized by the characteristic length $L=(D / \rho)^{1 / 4}$ where $D=E h^{3} / 12\left(1-\nu^{2}\right)=$ cylindrical bending stiffness of the ice plate; $\nu=$ its Poisson ratio. According to Irwin's relation, the energy release rate is $\mathcal{G}=K_{I}^{2} / E^{\prime}=N^{2} g(\alpha) / E^{\prime} h$. Here $E^{\prime}=E /\left(1-\nu^{2}\right)$ and $g(\alpha)$ is a dimensionless function:

$$
g(\alpha)=\pi \alpha\left[6 F_{M}(\alpha) e / h+F_{N}(\alpha)\right]^{2} \quad(\alpha=a / h)
$$

which is obtained by superposing the expressions for the stress intensity factor $K_{I}$ (given in handbooks), characterized by functions $F_{M}(\alpha)$ and $F_{N}(\alpha)$ for loading by bending moment $M$ and normal force $N ; a=$ crack depth, $e=-M / N=$ eccentricity (positive when the compression resultant is above the mid-plane).

To relate $M$ and $N$ to vertical load $P$, let us consider element 12341 of the plate (Fig. la and 2e,f,g), limited by a pair of opposite radial cracks and the initiating polygonal cracks (with zero depth at initiation). Since the cracks must form at the location of the maximum radial bending moment, the vertical shear force on the planes of these cracks is zero. The distance $R$ of the polygonal cracks from the vertical load $P$ may be expected to be proportional to the characteristic length $L$, and so we may set $R=\mu_{R} L$ where $\mu_{R}$ is assumed to be a dimensionless constant (Irwin's characteristic length of fracture is expected to have no effect because the initiation of polygonal cracks is governed by a strength criterion).

In each narrow radial sector, the resultant of the water pressure due to deflection $w$ (Fig. 2b,c) is located at a certain distance $r_{w}$ from load $P ; r_{w}$ must be proportional to $L$ because its solution must depend on only one parameter, $L$. Integration over the area of element 12341, taken as a semi-circle of radius $r_{w}$, yields the vertical resultant of water pressure acting on the whole element 12341 . Again, the distance of this resultant (whose magnitude it $P / 2$ ) from load $P$ must be proportional to $L$, i.e., may be written as $R_{w}=\mu_{w} L$ where the factor $\mu_{w}$ is dimensionless and is assumed to be a constant (which is justified when crack tip plasticity is negligible)

For simplicity, we assume $N$ and $M$ along the radial as well as polygonal cracks 


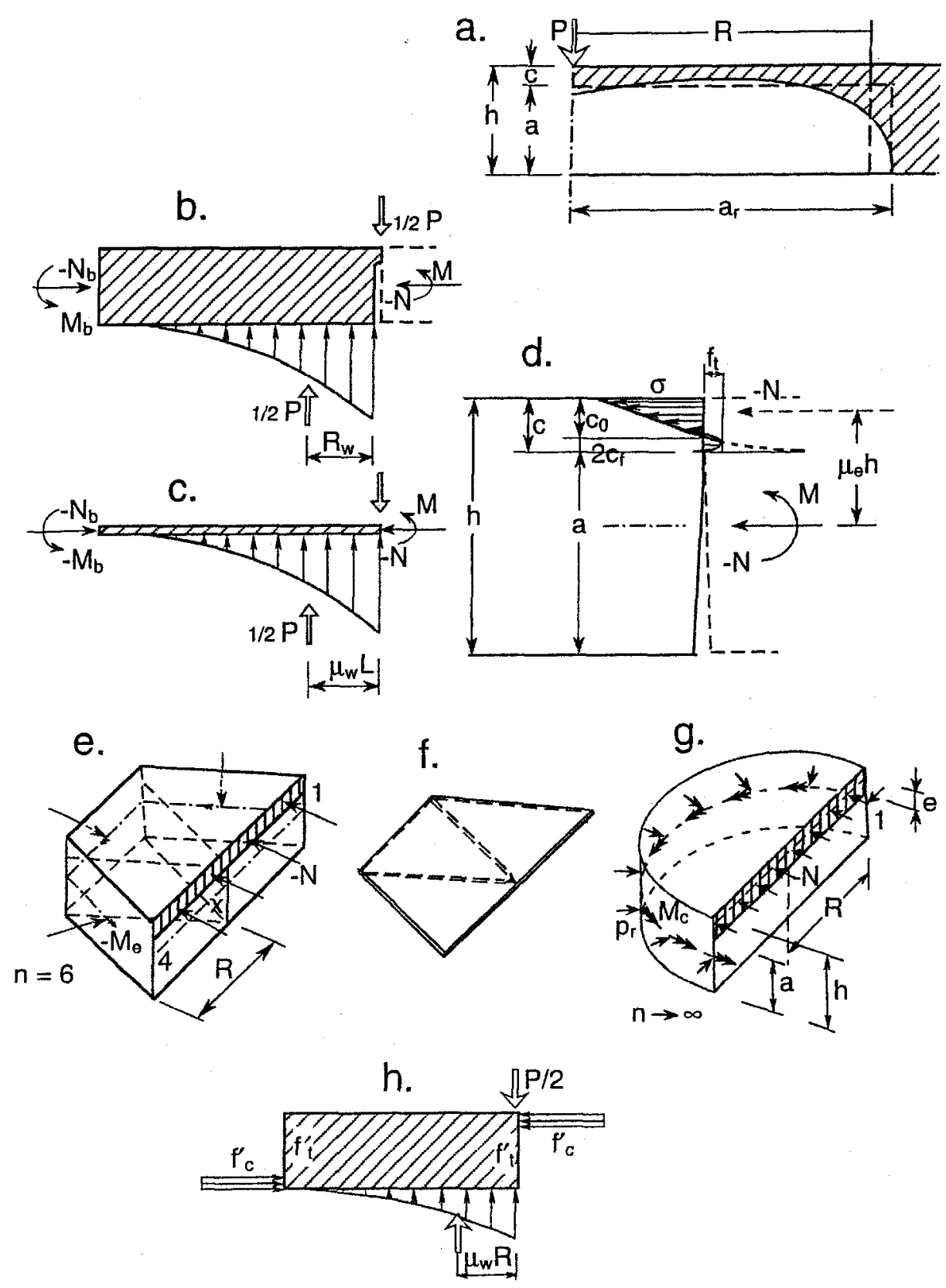

Figure 2: Analysis of vertical penetration fracture: (a) Crack profile and (b-h) forces acting on element 123401. to be uniform. The condition of equilibrium of horizontal forces acting on element 12341 in the direction normal to a radial crack then requires $N$ on the planes of the polygonal cracks to be equal to the $N$ acting in the radial crack planes (this becomes clear upon noting that the loading by $N$ along the entire circumference of element 12341 is in equilibrium with a two-dimensional hydrostatic stress in the horizontal plane).

The axial vectors of the moments $M_{c}$ acting on the polygonal sides are shown in Fig. 2e,g by double arrows. Summing the projections of these axial vectors from all the polygonal sides of the element, one finds that their moment resultant with axis in the direction 14 is $2 R M$, regardless of the number $n$ of radial cracks. So, upon setting $R=\mu_{R} L$, the condition of equilibrium of the radial cracks with the moments about axis 14 (Fig. 2b,c,e,g) located at mid-thickness of the cross section may be written as:

$$
2\left(\mu_{R} L\right) M+2\left(\mu_{R} L\right) M_{c}-\frac{1}{2} P\left(\mu_{w} L\right)=0
$$

Consider now the initiation of the polygonal cracks. It occurs when the norma stress $\sigma$ reaches the tensile strength $f_{t}^{\prime}$ of the ice. A layer of distributed microcracking, of some effective constant thickness $D_{b}$ that is a material property, will have to form at the top ice before the polygonal crack could (cf. Bažant and Li 1996 , for concrete). The polygonal cracks may be assumed to initiate when the average stress in layer $D_{b}$ reaches the tensile strength $f_{t}^{\prime}$, and since the average stress is roughly the elastically calculated stress for the middle of layer $D_{b}$, the criterion of bending crack initiation may simply be written as $\sigma_{b}+N / h=f_{t}^{\prime}$ where $\sigma_{b}=\left(12 M_{c} / h^{3}\right)\left(h-D_{b}\right) / 2=\left(6 M_{c} / h^{2}\right)\left(1-D_{b} / h\right)$. This criterion, however, can be correct only when $h$ is sufficiently larger than $D_{b}$, i.e., asymptotically for $h / D_{b} \rightarrow \infty$. The case $h<D_{b}$ is physically meaningless. For $h \approx D_{b}, M$ can be reasonably approximated as the plastic bending moment, which may be approximately taken as $1.5 \times$ larger than the elastic bending moment for the same material strength. This condition is satisfied by replacing the aforementioned initiation criterion with:

$$
\frac{6 M_{c}}{h^{2} q(\xi)}+\frac{N}{h}=f_{t}^{\prime}, \quad q(\xi)=\frac{2+\xi}{1+\xi}, \quad \xi=\frac{h}{D_{b}}
$$

This replacement is justified by noting the large-size asymptotic expansion $1 / q(\xi)=$ $\left(1+D_{b} / h\right) /\left(1+2 D_{b} / h\right)=\left(1+D_{b} / h\right)\left(1-2 D_{b} / h+(\cdot) / h^{2}+\ldots\right)=1-D_{b} / h+(\cdot) / h^{2}+$ $(\cdot) / h^{3}+\ldots$, and realizing that factor $1 / q(\xi)$ and the original factor $\left(1-D_{b} / h\right)$ are both valid only up to the first two terms of the asymptotic expansion in powers of $1 / h$, which are common to both (cf. Bažant and Chen 1997). The approximation by function $q(\xi)$ achieves the asymptotic matching of the size effects at both very large and very small sizes.

Now substitute $M=-N e=N \mu_{e} h$ into (2) ( $N$ is negative when compressive); $\mu_{e}=e / h \approx=$ constant $<0.5$ (according to the numerical results of Bažant and Kim, $1998, \mu_{e} \approx 0.45$, since the average crack depth $a$ at maximum load is about $0.8 h$ ). Then $M_{c}$ may be expressed from (2) and substituted into (3). Furthermore, one must take into account the condition of vertical propagation of the radial bending cracks, which may be written as $\mathcal{G}=G_{f}$ where $G_{f}$ is the fracture energy of ice. Thus, the critical value of normal force (compressive, with eccentricity $e$ ) may be written as

$$
N=-\sqrt{E^{\prime} G_{f} h / g(\alpha)}
$$


Algebraic rearrangements eventually lead to the following equation:

$$
\sigma_{N}=\frac{2 \mu_{R}}{3 \mu_{w}}\left\{\left[6 \mu_{e}+q(\xi)\right] \sqrt{\frac{E^{\prime} G_{f}}{h g(\alpha)}}+f_{i}^{\prime} q(\xi)\right\}
$$

To decide the value of $\alpha$, note that a finite fracture process zone (FPZ) of a certain characteristic depth $2 c_{f}$ which is a material property must exist at the tip of vertically propagating radial crack in ice. This zone was modeled in the numerical simulations of Bažant and Kim (1998) as a yielding zone. The tip of the equivalent LEFM crack lies approximately in the middle of the FPZ, i.e., at a distance $c_{f}$ from the actual crack tip, whose location is denoted as $a_{0}$. In structures of different sizes, the locations of the actual crack tip are usually geometrically similar, i.e., the value of $\alpha_{0}=a_{0} / h$ may be assumed to be constant when ice plates of different thicknesses $h$ are compared (Bažant and Planas 1998). Thus, denoting $g^{\prime}\left(\alpha_{0}\right)=\mathrm{d} g\left(\alpha_{0}\right) / \mathrm{d} \alpha_{0}$, one may introduce the approximation

$$
g(\alpha) \approx g\left(\alpha_{0}\right)+g^{\prime}\left(\alpha_{0}\right)\left(c_{f} / D\right)
$$

Substituting this into (5) and rearranging, one gets for the size effect the formula:

$$
\sigma_{N}=\frac{4 \mu_{R}}{\mu_{w}}\left[\mu_{e}+\frac{q(\xi)}{6}\right] \sqrt{\frac{E^{\prime} G_{f}}{h g\left(\alpha_{0}\right)+c_{f} g^{\prime}\left(\alpha_{0}\right)}}+\frac{\mu_{R}}{3 \mu_{w}} q(\xi) f_{t}^{\prime}
$$

Consider now the special case in which the size dependence of $q(\xi)$ is neglected i.e. $q(\xi)=1$ (this is justified when $\xi=h / D_{b}$ is large because $q(\xi)$ approaches 1 as $1 / h$, which is much faster than the asymptotic trend of $(8)$, which is $1 / \sqrt{h}$ ). In this special case, (7) reduces to the classical size effect law with non-zero residual strength $\sigma_{r}$ (proposed by Bažant, 1987):

$$
\sigma_{N}=\sigma_{0}\left(1+\frac{h}{h_{0}}\right)^{-1 / 2}+\sigma_{r}
$$

in which $\quad \sigma_{0}=\frac{4 \mu_{R} \mu_{e}}{\mu_{w}} \sqrt{\frac{E^{\prime} G_{f}}{c_{f} g^{\prime}\left(\alpha_{0}\right)}}, \quad h_{0}=c_{f} \frac{g^{\prime}\left(\alpha_{0}\right)}{g\left(\alpha_{0}\right)}, \quad \sigma_{r}=\frac{\mu_{e}}{3 \mu_{w}} f_{t}^{\prime}$

This formula was shown to agree with the numerical simulations by Bažant and Kim (1998), which in turn were shown not to disagree with the experimental data that exist (Fig. 1h,j).

In theory, $\sigma_{N}$ for $h \rightarrow 0$ could be calculated from plasticity because the strength limit is reached simultaneously in the entire cross section (as $h \ll$ fracture process zone length). But in practice the plastic limit analysis is inapplicable because the foundation provided by water behaves always elastically, causing that there is no plastic limit load (unless water leaks to the top of ice, but even in that case the load capacity depends on inelastic deflections whose calculation does not lend itself to simple formulae).

\section{Horizontal Force Exerted on Obstacle by Moving Ice}

Another important problem of scaling is the force $P$ that a moving ice plate of thickness $h$ exerts on a fixed structure, idealized as a rigid circular cylinder of

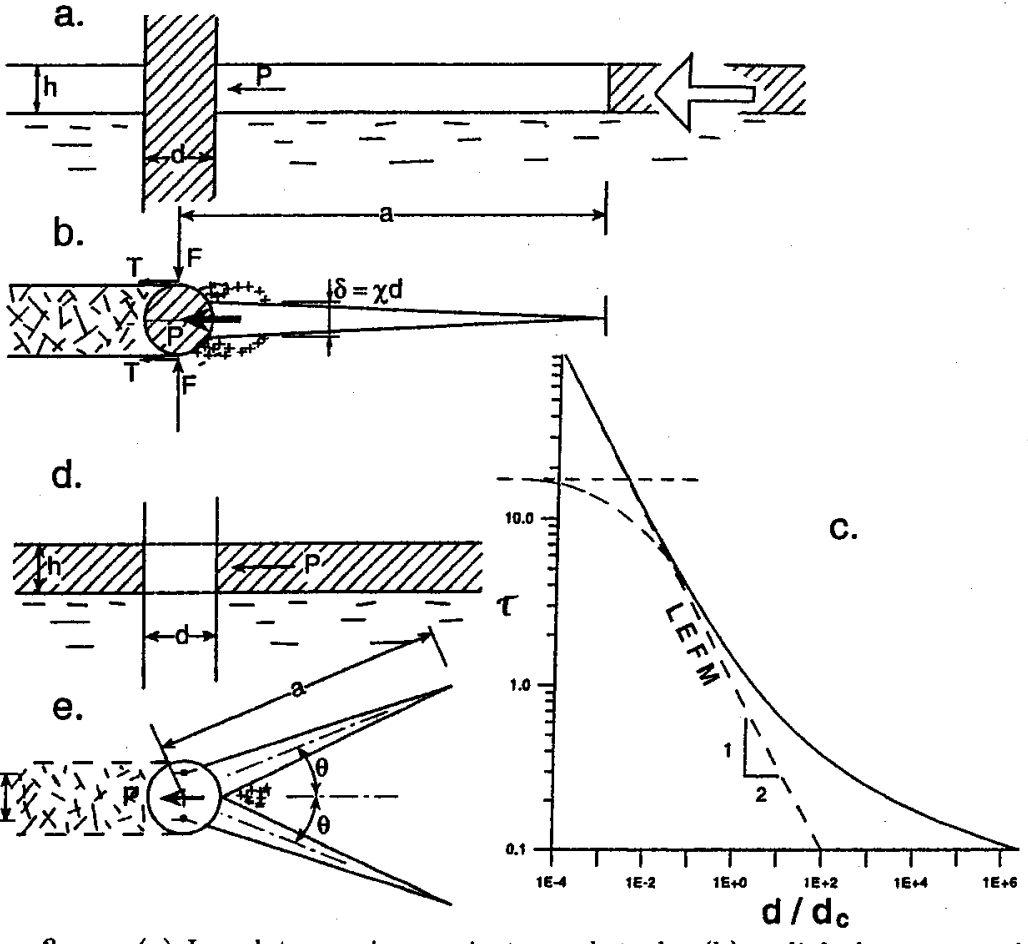

Figure 3: (a) Ice plate moving against an obstacle, (b) radial cleavage crack, (c) resulting size effect when the cohesive zone length is ignored, (d) diverging V-cracks.

diameter $d$. The nominal strength of the structure may in this case be defined as $\sigma_{N}=P / h d$. Several mechanisms of break-up are possible.

One is the elastic buckling of the floating plate (e.g. Slepyan 1990). Although the present interest is in fracture, it may be mentioned that the elastic buckling failure exhibits a reverse size effect of the type $\sigma_{N c r}=\kappa(d / h) \sqrt{\rho E^{\prime}} \sqrt{h}$ (Bažant 2000) where $\kappa$ is a dimensionless parameter depending on $d / h$. Thus, only very thin floating plates can fail by buckling.

Consider now a long radial cleavage crack in the ice plate, propagating against the direction of ice movement (Fig. 3a,b). The ice exerts on the structure a pair of transverse force resultants $F$ and a pair of tangential forces $T$ in the direction of movement; $T=F \tan \varphi$ where $\varphi=$ effective friction angle. Considering the ice plate as infinite, we have $K_{I}=(F / h) \sqrt{2 / \pi a}$ The energy release rate is

$$
\mathcal{G}=\frac{1}{h}\left[\frac{\partial \Pi_{*}}{\partial a}\right]_{F}=\frac{1}{h} \frac{\mathrm{d}}{\mathrm{d} a}\left[\frac{1}{2} C(a) F^{2}\right]=\frac{F^{2}}{2 h} \frac{\mathrm{d} C(a)}{\mathrm{d} a}
$$

where $a=$ crack length ((Fig. 3a,b) and $C(a)=$ load-point compliance of forces $F$. Using Irwin's relation, we have $\mathcal{G}=K_{I}^{2} / E=2 F^{2} / \pi E h^{2} a$. Equating this to (10), we thus get $\mathrm{d} C(a) / \mathrm{d} a=4 / \pi E h a$. This expression may now be integrated from $a=d / 2$ (surface of structure, Fig. 3a,b) to $a$. Thus one gets $C(a)$, and from it the opening deflection $\delta=C(a) F=(4 F / \pi E h) \ln (2 a / d)$. Now note that 
there is likely to be at least some amount of local ice crushing at the structure, and so the relative displacement between the two flanks of the crack must be less than $d$. Setting $\delta=\chi d(\xi<1)$, we obtain from the foregoing expression for $\delta$ the relation $a=\frac{1}{2} d \exp (\pi E h \chi d / 4 F)$ (note that $a / d$ is not constant but increases with $d$; hence, the fracture modes are not geometrically similar, and so the LEFM power scaling cannot be expected to apply). Now we substitute this into $K_{I}=(F / h) \sqrt{2 \pi / a}$, set $K_{I}=K_{c}=\sqrt{E G_{f}}$ where $K_{c}=$ fracture toughness of ice, and write $\sigma_{N} h d=P=2 T=2(F \tan \varphi)$ where $\varphi=$ friction angle. After some rearrangements, this yields the size effect relation

$$
d / d_{c}=\tau^{-2} \mathrm{e}^{1 / \tau}
$$

in which $\tau=\sigma_{N} / \sigma_{c}$ and $d_{c}$ and $\sigma_{c}$ are constants defined as $d_{c}=4 G_{f} / \pi E \chi^{2}, \quad \sigma_{c}=$ $\frac{1}{2} \pi E \chi \tan \varphi$. Eq. (11), plotted in Fig. 3c, represents the law of radial cleavage size effect in an inverted form. Note that, for $d \ll d_{c}, \sigma_{N} \approx \sqrt{d_{c} / d}$, which is the LEFM scaling for similar cracks.

So far, the length $2 c_{f}$ of the cohesive zone of the radial cleavage crack was considered negligible compared to $a$. If this is not so, then the $\log$-log size effect plot (dashed curve) is found to start from the left with a horizontal asymptote and then gradually approach the curve in Fig. 3c (see the formula in Bażant 2001). As seen in Fig. 3c, the size effect is getting progressively weaker with increasing $d$ (although no horizontal asymptote is approached). The reason is that the cracks are dissimilar, i.e., the ratio $a / d$ increases with $d$.

Another observed mechanism (e.g., Sanderson 1988, ch. 7) consists of diverging V-shaped cracks; Fig. 3d,e. To estimate in a crude manner the complementary energy $\Pi^{*}$, we may consider only the stresses within the wedge between the cracks (Fig. 3f). From a well-known solution (Timoshenko and Goodier, 1970), $\sigma_{r}=$ $-P k_{\theta} \cos \varphi / r h, \sigma_{\varphi}=\sigma_{r \varphi}=0$ where $\sigma_{r}, \sigma_{\varphi}$ and $\sigma_{r \varphi}$ are the stress components in polar coordinates $r, \varphi$, and $k_{\theta}=1 /\left(\theta+\frac{1}{2} \sin 2 \theta\right), \theta$ being the inclination angle of the cracks (Fig. 3d). The displacement at $r=d / 2$ (structure surface) is $u=$ $\int_{d / 2}^{\infty}\left(\sigma_{r} / E\right) \mathrm{d} r=\left(P k_{\theta} / E h\right) \ln (2 a / d)$. Then $\Pi^{*}=\frac{1}{2} P u=\left(P^{2} k_{\theta} / 2 E h\right) \ln (2 a / d)$. The complementary energy before fracture may be estimated as the value of $\Pi^{*}$ for $\theta=\pi$, i.e. $\Pi_{0}^{*} \approx\left(P^{2} / 2 \pi E h\right) \ln (2 a / d)$. The total energy release due to $V$-cracks in the ice plate is $\Delta \Pi^{*}=\Pi^{*}-\Pi_{0}^{*}$. The condition $\left[\partial \Delta \Pi^{*} / \partial a\right]_{P}=2 h G_{f}$ yields

$$
\sigma_{N}=\frac{P}{h d} \approx \frac{2}{d} \sqrt{\frac{E G_{f}}{\pi^{-1}-k_{\theta}}} \sqrt{a}
$$

To determine crack length $a$ and angle $\theta$, one could use two conditions: 1) the opening displacement at the crack mouth, $\delta$, must be equal to $\chi d /(2 \cos \theta)$, which means that the load-point displacement of force $P$ must be $u=(\chi d / 2) \tan \theta$, and 2) $P$ should be minimized with respect to $\theta$. However, the solution is quite complicated and will not be pursued here. Besides, there is also the question of a possible simultaneous axial (radial) cleavage crack, and the question of simultaneous ice crushing. Unlike the radial cleavage fracture, the V-shaped crack mechanism cannot accommodate continuous movement of the ice and can occur only from time to time.

A further possible break-up mechanism is the compression fracture of the ice plate in contact with the obstacle. This mechanism also leads to a pronounced size effect. A simplified formula for it was derived in Bažant and Xiang (1997) and Bažant (2000) (also Bažant 2001, 2002).

Finally, the ice floe can fracture globally, upon impact. It can be approximately treated as a deep beam loaded by distributed forces representing the inertia forces, and by a concentrated reaction from the obstacle. This type of fracture of quasibrittle materials has been treated in various works, and a strong size effect due to energy release has been shown to exist (for a review, see Bažant and Chen 1997, Bažant 1999, 2001, 2002).

\section{Acknowledgment}

Partial financial support under grant N00014-91-J-1109 from the Office of Naval Research and grant CMS-9713944 from the National Science Foundation, both to Northwestern University, is gratefully acknowledged.

\section{References}

Ashton, G. (ed.) 1986. River and Lake Ice Engineering. Water Resources Publications. Atkins, A.G. 1975. Icebreaking modeling. J. of Ship Research 19(1): 40-43.

Bažant, Z.P. 1984. Size effect in blunt fracture: concrete, rock, and metal. J. of Engrg. Mech. ASCE 110: 518-535.

Bažant, Z.P. 1985. Fracture mechanics and strain-softening in concrete. Preprints, U.S. Japan Seminar on Finite Element Analysis of Reinforced Concrete Structures, Tokyo, Vol. 1, pp. 47-69.

Bažant, Z.P. 1987. Fracture energy of heterogeneous material and similitude. Preprints, SEM-RILEM Int. Conf. on Fracture of Concrete and Rock (held in Houston, Texas) ed. by S. P. Shah and S. E. Swartz, publ. by SEM (Soc. for Exper. Mech.) 390-402.

Bažant, Z.P. 1992. Large-scale thermal bending fracture of sea ice plates. J. of Geophysical Research 97 (C11): 17,739-17,751.

Baz̃ant, Z.P. 1997a. Scaling of quasibrittle fracture: asymptotic analysis. Int. J. of Fracture 83 (1): 19-40.

Bažant, Z.P. 1997b. Scaling of quasibrittle fracture: Hypotheses of invasive and lacunar fractality, their critique and Weibull connection. Int. J. of Fracture 83 (1): 41-65.

Bažant, Z.P. 1999. Size effect on structural strength: a review. Archives of Applied Mechanics (Ingenieur-Archiv, Springer Verlag) 69: 703-725.

IUTA Z.P. 2000. Scaling laws for brittle failure of sea ice. Preprints distributed at IUTAM Workshop on Scaling Laws in Ice Mechanics and Ice Dynamics, held at University of Alaska, Fairbanks, June 2000, J.P. Dempsey et al., eds., pp. 1-23.

ažant, Z.P. 2001a. Scaling of Structural Strength. Hermes Scientific Publications, Oxford and Paris.

Bažant, Z.P. 2001b. Scaling of failure of beams, frames and plates with softening hinges. Meccanica (Italy) (special issue honoring Giulio Maier), in press.

ažant, Z.P. 2002. Scaling of Sea Ice Fracture. I. Vertical Penetration. II. Horizontal Load from Moving Ice. ASME Journal of Applied Mechanics, in press.

Bażant, Z.P., and Cedolin, L. 1991. Stability of structures: Elastic, inelastic, fracture and damage theories, Oxford University Press, New York.

Bažant, Z.P., \& Chen, E.-P. 1997. Scaling of structural failure. Applied Mechanics Reviews ASME 50 (10): 593-627.

Bažant, Z.P., and Guo, Z. 2001. Size effect of softening inelastic hinges: II. Sea ice under vertical line load. ASCE J. of Engrg. Mech., submitted to.

Bažant, Z.P., and Kim, J.-K. 1985. Fracture theory for nonhomogeneous brittle materials with application to ice. Proc. ASCE Nat. Conf. on Civil Engineering in the Arctic Offshore - ARCTIC 85, San Francisco, L. F. Bennett (ed.), ASCE, New York, pp

Bažant, Z.P., and Kim, Jang-Jay H. 1998. Size effect in penetration of sea ice plate with part-through cracks. I. Theory. J. of Engrg. Mechanics ASCE 124 (12): 1310-1315 with discussions and closure in 126 (4): 438-442 (2000)

Bažant, Z.P., and Kim, Jang-Jay H. 1998. Size effect in penetration of sea ice plate with part-through cracks. II. Results. J. of Engrg. Mechanics ASCE 124 (12): 1316-1324; with discussions and closure in 126 (4): 438-442 (2000).

Bažant, Z.P., Kim, J.J., \& Li, Y.-N. 1995. Part-through bending cracks in sea ice plates: Máthematical modeling. ICE MECHANICS-1995, J.P. Dempsey \& Y. Rajapakse (eds.), ASME AMD-Vol. 207, 97-105. 
Bažant, Z.P., and Li, Y.-N. 1994. Penetration fracture of sea ice plate: Simplified analysis and size effect. J. of Engrg. Mech. ASCE 120 (6): 1304-1321.

Bažant, Z.P., and Li, Y.-N. 1995. Penetration fracture of sea ice plate. Int. J. Solids Structures 32 (No. 3/4): 303-313.

Bažant, Z.P., and Planas, J. 1998. Fracture and size effect in concrete and other quasibrittle materials. CRC Press, Boca Raton, Florida.

Bažant, Z.P., and Xiang, Y. 1997. Size effect in compression fracture: splitting crack band propagation. $J$. of Engrg. Mechanics ASCE 123 (2): 162-172.

Dempsey, J.P. 1991. The fracture toughness of ice. Ice Structure Interaction, S.J. Jones, R.F. McKenna, J. Tilotson and I.J. Jordaan, Eds., Springer-Verlag, Berlin, pp. 109145.

Dempsey, P.P. 2000. Discussion of Size effect in penetration of ice plate with part-through cracks. I. Theory, II. Results. by Z.P. Bažant and J.J.H. Kim, J. of Engrg. Mech. 126 (4): 438; with authors' rebuttal, 438-442.

Dempsey, J.P., Adamson, R.M., and Mulmule, S.V. 1995, Large-scale in-situ fracture of ice. Proc., FRAMCOS-2, Wittmann, F.H., ed., AEDIFICATIO Publishers, D-79104 Freiburg, Germany, pp. 675-684.

Dempsey, J.P., Adamson, R.M., and Mulmule, S.V. 1999b. Scale effects on the in situ tensile strength and fracture of ice: Part II.: First-year sea ice at Resolute, N.W.T.. Int. J. of Fracture 95: $346-378$.

Dempsey, J.P., DeFranco, S.J., Adamson, R.M., and Mulmule, S.V. 1999a. Scale effects on the in situ tensile strength and fracture of ice: Part I.: Large grained freshwater ice at Spray Lakes Reservoir, Alberta. Int. J. of Fracture 95: 325-345.

Dempsey, J.P., Slepyan, L.I., and Shekhtman, I.I. 1995. Radial cracking with closure. Int. J. of Fracture 73 (3): 233-261.

DeFranco, S.J., and Dempsey, J.P. 1992. Nonlinear fracture analysis of saline ice: Size, rate and temperature effects. Proc. of the 11th IAHR Symposium, Banff, Alberta, Vol.3, pp. 1420-1435.

DeFranco, S.J., and Dempsey, J.P. 1994. Crack propagation and fracture resistance in

saline ice. J. Glaciology 40: 451-462.
DeFranco, S.J., Wei, Y., and Dempsey, J.P. 1991. Notch acuity effects on fracture of saline ice. Annals of Ğlaciology 15: 230-235.

Frankenstein, E.G. 1963 . Load test data for lake ice sheet. Technical Report 89, U.S. Army Cold Regions Research and Engineering Laboratory, Hanover, New Hampshire. Frankenstein, E.G. 1966. Strength of ice sheets. Proc., Conf. on Ice Pressures against Struct.; Tech. Memor. No. 92, NRCC No. 9851, Laval University, Quebec, National Research Council of Canada, Canada, pp. 79-87.

Goldstein, R.V., and Osipenko, N.M. 1993. Fracture mechanics in modeling of icebreaking capability of ships. J. of Cold Regions Engrg. ASCE 7 (2): 33-43

Li, Y.-N., and Bažant, Z.P. 1994. Penetration fracture of ice plate: $2 \mathrm{D}$ analysis and size effect. J. of Engrg. Mech. ASCE 120 (7): 1481-1498.

$\mathrm{Li}, \mathrm{Z}$, and Bażant, Z.P. 1998. Acoustic emissions in fracturing sea ice plate simulated by particle system. J. of Engrg. Mechanics ASCE 124 (1): 69-79.

Lichtenberger, G.J., Jones, J.W., Stegall, R.D., and Zadow, D.W. 1974. Static ice loading tests Resolute Bay - Winter 1973/74. APOA Proj. No. 64, Rep. No. 745B-74-14, (CREEL Bib \# 34-3095), Sunoco Sci. \& Technol., Rechardson, Texas.

Kerr, A.D. 1996. Bearing capacity of floating ice covers subjected to static, moving, and oscillatory loads. Appl. Mech. Rev., ASME Reprint 49 (11): 463-476.

Mulmule, S.V., Dempsey, J.P., and Adamson, R.M., 1995. Large-scale in-situ ice fracture experiments - part II: modeling efforts, in ice mechanics - 1995 . ASME.Joint Applied Mechanics and Materials Summer Conference, AMD - MD 1995, University of California, Loas Angeles, June, pp. 28-30.

Palmer, A.C., et al. 1983. Annals of Glaciology 4: 216-221.

Ponter, A.R.S. 1983. Cold Regions Sci. E Tech. 8: 189-118.

Rice, J.R. and Levy, N. 1972. The part-through surface crack in an elastic plate. J. Appl. Mech. ASME 39: 185-194.

Sanderson, T.J.O. 1988. Ice Mechanics: Risks to Offshore Structures, Graham and Trotman Limited, London.

Slepyan, L.I. 1990. Modeling of fracture of sheet ice. Mechanics of Solids (transl. of Izv. AN SSSR Mekhanika Tverdoga Tela), pp. 155-161.

Sodhi, D.S. 2000. Discussion of Size effect in penetration of ice plate with part-through cracks. I. Theory, II. Results. by Z.P. Bažant and J.J.H. Kim, J. of Engrg. Mech. 126 (4): 438-440; with authors' rebuttal, 438-442.

Timoshenko, S.P., \& Goodier, J.N. 1970. Theory of elasticity. 3rd ed. McGraw Hill, NY. 